\title{
Modernizando desde abajo. La reconversión del caciquismo y la política de masas en las ciudades catalanas (1901-1923)
}

\author{
Maria Gemma Rubí CASALS \\ Universitat Autònoma de Barcelona \\ Mariagemma.rubi@uab.cat
}

Recibido: 26/05/2009

Aceptado: 07/07/2011

\begin{abstract}
RESUMEN
El origen de este artículo reside en una comunicación que presenté al Congreso Internacional "Modernizar España" (1898-1914) que se celebró en la Universidad Complutense de Madrid en abril de 2006. El enfoque utilizado es el de la historia social de la política y se centra en el análisis de las prácticas políticas y de las actitudes adoptadas por las élites partidistas catalanas a lo largo del régimen político de la Restauración. Ante todo, se insiste en la capacidad de resistencia de las prácticas caciquiles que se percibe a partir de 1900, a pesar de la descomposición precoz del turno dinástico en Cataluña, y del progreso imparable de la autentificación del sufragio. A este nuevo caciquismo lo hemos llamado "caciquismo renovado o reconvertido" que convivió con la movilización electoral y el pluralismo político, elementos propios de una politización democrática embrionaria, y que se apoyó en las organizaciones de intereses que proporcionaron votos a cambio de favores y de prebendas.
\end{abstract}

Palabras clave: caciquismo, democratización, Cataluña, Restauración.

\section{Modernization From Below. The Renewal of the "Caciquismo" and the Mass Politics in the Catalan Cities (1901-1923)}

\begin{abstract}
This paper has its origin in an essay presented at the International Congress: Modernizing Spain (18981914), which was held at the Universidad Complutense de Madrid in April 2006. The approach taken here is that of the social history of politics, focusing on the analysis of political practices and attitudes adopted by the elites leading Catalan parties during the political regime of the Bourbon Restoration. Special emphasis is placed on the resilience of caciquism practices noticeable from 1900 despite the early disintegration of the system known as Turno Pacifico and the unstoppable progress of vote authentication. This new caciquism is referred to as "renewed or restructured caciquism" in the paper, since it coexisted with electoral mobilization and political pluralism -characteristic elements of embryonic democratic politicization- and was underpinned by interest groups providing votes in return for privileges and favours.
\end{abstract}

Key words: Caciquism, Bourbon Restoration, Political elites, Modernization, Catalonia.

Sumario: 1. Lucha política y sufragio censatario. 2. El sufragio universal multiplica los esfuerzos para controlar el voto. 3. El despertar cívico de las clases medias y el descuaje del caciquismo. 4. La entronización de un nuevo bipartidismo catalanista-republicano. 5. Pluralismo político, competencia electoral y clientelismo. 6. Nuevas formas de partido surgen en la Cataluña de principios del siglo XX. 7. Los ingredientes del cambio. 8. Un caciquismo renovado. 9. Un callejón sin salida democrática. 
El objetivo del presente artículo es poner de relieve cómo se produjo en Cataluña la descomposición del sistema caciquil de la Restauración analizando la transformación de las prácticas políticas, así como de las actitudes y comportamientos manifestados por las diferentes élites partidistas de las ciudades catalanas ${ }^{1}$. Un análisis que partirá prioritariamente de un estudio de caso basado en una investigación empírica que nos servirá de antemano para conocer los ritmos de la modernización política que experimentaron los distritos y circunscripciones catalanes ${ }^{2}$. Para este cometido hemos elegido la ciudad de Manresa situada en el corazón geográfico de Cataluña como ejemplo y modelo extensible a otras ciudades de tamaño medio, referentes imprescindibles de la densa Cataluña urbana ${ }^{3}$. En 1897 era la cuarta población más importante de esta región en cuanto a peso demográfico y desarrollo económico después de Barcelona, Reus y Tarragona. El motor principal de su economía era la industria algodonera que en los años treinta del siglo XX pasó a ocupar 8000 obreros sobre una población total de 35.000 habitantes. Sin embargo, desde el inicio del siglo XX su economía experimentó una diversificación notable con la incorporación de las industrias metalúrgica, eléctrica y del caucho, respectivamente, y la expansión de un importante comercio al detalle y al por mayor que servía a las comarcas de la Cataluña central. Mientras tanto las artes y oficios, y sobre todo el sector agrícola fueron perdiendo peso específico en beneficio de los sectores fundamentalmente industrial y progresivamente de servicios.

${ }^{1}$ Este artículo constituye una versión revisada y ampliada de la comunicación que presenté al Congreso Internacional Modernizar España (1898-1914). Proyectos de reforma y apertura internacional en torno a la Conferencia de Algeciras que tuvo lugar en la Universidad Complutense de Madrid el mes de abril de 2006. Su origen parte de una investigación que desembocó en Tesis Doctoral: El mundo de la política en la Cataluña urbana de la Restauración. El caso de una ciudad industrial, Manresa (1875-1923) (2003), fruto de un convenio de cotutela entre la Ecole des Hautes Études en Sciences Sociales y la Universitat Autònoma de Barcelona. También de mi libro, Entre el vot i la recomanació. Partits, mobilització electoral i canvi polític. Manresa, 1899-1923, Manresa, Angle Editorial, 1995. Y de los libros que son fruto de la investigación doctoral: El caciquisme i el despertar de la societat de masses. Manresa, 1875-1923, Manresa, Centre d'Estudis del Bages, 2005, y, Els catalans i la política en temps del caciquisme. Manresa, 1875-1923, Vic, Eumo Editorial, 2006. Finalmente, esta investigación se ha visto enriquecida con el anàlisis de la actuación de los parlamentarios catalanes durante la Restauración a través de mi participación como investigadora en los proyectos "La cuestión catalana en la política espanyola del siglo XX" (BHA2002-01307) y "Diccionario biográfico de los parlamentarios de Cataluña. Segunda fase. Periodo 1869-1901" (HUM 2005-01485).

${ }^{2}$ Una panorámica global en Josep Armengol; Gemma Rubí, "Cataluña” en VARELA ORTEGA, José (dir): El poder de la influencia. Geografía del caciquismo en España (1875-1923), Madrid, Marcial Pons/Centro de Estudios Constitucionales, 2001, pp. 237-282. Sobre el papel de las ciudades en la modernización de la España contemporánea, especialmente, GARCÍA DELGADO, José Luis (ed.): Las ciudades en la modernización de España. Los decenios interseculares. VIII Coloquio de Historia cotemporánea de España, Madrid, Siglo XXI, 1992; BONAMUSA, Francesc; SERRALLONGA, Joan (eds.): La sociedad urbana en la España contemporánea. Segundo Congreso de la Asociación de Historia contemporánea, Barcelona, Asociación de Historia contemporánea, 1994; y, más recientemente, GÓMEZ-FERRER, Guadalupe; SÁNCHEZ, Raquel (ed.): Modernizar España. Proyectos de reforma y apertura internacional (1898-1914), Madrid, Biblioteca Nueva, 2007.

${ }^{3}$ Véanse mis artículos "El canvi polític de la Restauració. Manresa, 1875-1923" en L'Avenç, n 29, Febrero 2005, pp. 6-9; y, "Escaños, votos e irregularidades. Los caprichos de la política en la Cataluña de la Restauración, 1875-1923” en Hispania Nova (2007). 
En definitiva, la ciudad nos proporciona un marco idóneo para estudiar el caciquismo como sistema de poder y su reconversión en un contexto de politización casi permanente en la calle y en las urnas. Un estudio de caso que nos permite acotar en toda su complejidad el proceso de evolución del liberalismo ochocentista a un primer estadio del liberalismo democrático que poco tenía que ver con la democracia de partidos que se desarrolló en Europa a partir de la segunda guerra mundial. Un tránsito poco analizado por la historiografía política catalana, mucho más pendiente de estudiar el catalanismo y su proyección en la política española de aquellos años ${ }^{4}$ Profundizar en los entresijos de esta etapa intermedia entre el liberalismo de notables a la primigenia política de masas es uno de los objetivos prioritarios de la línea de investigación en la que se sustenta este artículo.

Durante los primeros decenios del siglo XX la democracia se abrió paso en el contexto de un sistema político que solamente era liberal, pese haber reconocido los derechos políticos a los ciudadanos de sexo masculino. No obstante, no llegó a cristalizar en parte porque las reglas de juego del sistema lo impidieron. Una democracia muy limitada que avanzaba lentamente y a menudo con tropezones en la senda de un imperio de la ley que se asentaba en unas bases muy débiles y que tenía que luchar contra unas prácticas políticas pensadas para sociedades socialmente y políticamente desmovilizadas. Una gran paradoja presidió la vida política de estos años: el sufragio universal masculino, recuperado en 1891, amplió notablemente la representación política de la ciudadanía, pero la supervivencia del régimen dependía escrupulosamente del control riguroso del voto que tenían que ejercer las autoridades gubernamentales, porque esta era la espina dorsal del régimen surgido de la constitución de 1876.

En Cataluña, como en otras partes, la ingerencia sistemática gubernamental que hacía posible el turno dinástico, y por tanto, la alternancia pacífica de los dos grandes partidos de la Restauración funcionó durante unos años casi de forma automática. Especialmente en aquellos distritos electorales donde se había sofocado la voz de las clases medias y populares, mediante la fuerza aplicando métodos coactivos, o bien, de forma espontánea expresando un sabio desinterés por una vida política manipulada desde arriba que ignoraba y excluía a buena parte de la ciudadanía 5 .

\footnotetext{
${ }^{4}$ A pesar del peso específico de las ciudades en la vida política de la Cataluña de la Restauración, a parte de Manresa, sólo dos ciudades han sido objeto de una profunda investigación. Son Vic en la provincia de Barcelona (TORNAFOCH Xavier: Del caciquisme a la democràcia. Política i eleccions a Vic (1900-1931), Vic, Eumo Editorial, 2006) y la ciudad de Tárrega en la de Lleida (CAPDEVILA, Joaquim: Tàrrega (1898-1923): societat, política i imaginari, Barcelona, Publicacions de l'Abadia de Montserrat, 2008). Aproximaciones parciales sobre otras ciudades las tenemos en algunos trabajos contenidos en el libro de MIR, Conxita (ed.): Actituds politiques i control social a la Catalunya de la Restauració (1875-1923), Lleida, Virgili-Pagès, 1989. Recientemente sobre la ciudad de Barcelona, IZQUIERDO, Santiago: "La renovació i la democratització de les pràctiques polítiques a la ciutat de Barcelona: la gestió municipal del doctor Robert" en X Congrés d'Història de Barcelona. Dilemas de la fi de segle, 1874-1901, Barcelona, Institut de Cultura/Arxiu Històric de la ciutat de Barcelona, 2007.

${ }^{5}$ La vida político-electoral de Cataluña durante la Restauración la analizo junto a Josep Armengol en VARELA ORTEGA, José (dir.): El poder de la influencia. La geografía del caciquismo en España, op. cit.
} 
Una vez desarticulado el turno se produjo un proceso de autentificación de los procesos electorales a tenor del impulso regenerador y moralizador de la vida política que estaban desarrollando los partidos esencialmente antidinásticos, aunque compartido en parte por algunos sectores de las mismas fuerzas del sistema. De la política de notables se pasó a la política de masas. Sin embargo, hubo una etapa de reacomodación donde convivió la tradición con la modernidad, y el clientelismo con la movilización de la opinión y la captura de votos. El voto auténtico progresó lentamente sobre todo en los núcleos urbanos en los que no era tan fácil manipular la voluntad electoral ${ }^{6}$. La crisis del sistema y las limitaciones de la modernización política acabaron por abortar un proceso de apertura democrática que reconduciría, después del periodo dictatorial, el régimen republicano.

\section{Lucha política y sufragio censatario}

En Manresa, la Restauración empezó en un ambiente presidido por la crisis social, el endeudamiento crónico del erario municipal y por el mutismo de la opinión pública ${ }^{7}$. El proyecto restaurador conllevó el silencio forzado de la opinión ciudadana, la represión indiscriminada a raíz del motín de los consumos acaecido en 1878 y, la restauración de la hegemonía social de la Iglesia católica y de los sectores políticos afines. En este sentido, la Restauración borbónica supuso, como en todas partes, un claro giro conservador. Este cambio de rumbo se vivió con mucha más intensidad desde el momento que hasta el año 1885 el gobierno local estuvo en manos de los sectores ultracatólicos, carlistas y antiguos moderados. En realidad, estos eran unos grupos que jugaban la carta alfonsina pero que socialmente y en la esfera religiosa eran mucho más conservadores. La contraofensiva que se concretó en la persecución de los grupos republicanos y demócratas, del movimiento obrero y en la recuperación del ascendente social de la Iglesia.

Este flujo recatolizador alimentó una brecha muy honda entre los partidarios del progreso y los que lo eran de la involución y del inmovilismo. A partir de 1885, los republicanos obtuvieron representación política en los equipos de gobierno municipal. Los que muy pronto aprendieron el juego caciquil fueron los republicanos castelarinos, los posibilistas, mientras las otras familias republicanas fluctuaban del retraimiento a la participación soñando con el regreso del añorado régimen republicano. Las divisiones internas fueron así la nota predominante, mientras la actitud pragmática del republicanismo posibilista le permitió ocupar algunas alcaldías, como así sucedió.

A medida que los partidos de la oposición, especialmente los republicanos, intervinieron en las luchas por el poder local, el llamado voto verdad progresó sobre

${ }^{6}$ El magnífico estudio sobre el comportamiento electoral urbano en la España de la Restauración entre 1910 y 1923 así lo corrobora. Ver FORNER, Salvador et al. : "Modernización social y comportamiento electoral urbano en España, 1910-1923" en Democracia, elecciones y modernización en Europa. Siglos XIX y XX, Madrid, Cátedra, 1997, pp. 241-293.

${ }^{7}$ RUBI, Gemma: El caciquisme i el despertar de la societat de masses. Manresa, 1875-1901, op. cit. 
todo en los distritos urbanos de la ciudad, y en menor medida en los municipios de la comarca. Así, durante la etapa del sufragio restringido no todas las elecciones fueron fraudulentas, sino que, algunas, las que menos, fueron limpias. En determinados comicios legislativos, como los parciales de mayo de 1887, para citar un ejemplo, ganaron los posibilistas en la ciudad, mientras que gracias al conjunto del distrito el candidato gubernamental pudo obtener el acta.

\section{El sufragio universal multiplica los esfuerzos para controlar el voto}

La recuperación del sufragio universal masculino en 1890 para los varones mayores de 25 años no se tradujo en una competición electoral abierta entre los partidos del sistema, puesto que se continuó prescindiendo grosso modo del electorado. No obstante, la actividad de "fabricar" mayorías parlamentarias desde el Ministerio de Gobernación tropezó progresivamente con mayores obstáculos, especialmente en aquellos distritos donde había una oposición real, la que procedía de los partidos de arraigo popular. Aun así, aunque se aumentó el número de elecciones protestadas, no se acrecentó en la misma medida el de las elecciones que finalmente fueron anuladas.

En el distrito de Manresa los años noventa del siglo XIX significaron paradójicamente el perfeccionamiento del sistema de turno, cuando se pudieron identificar como tales a los que protegían los intereses de los dos partidos del sistema, liberales y conservadores, respectivamente, que al mismo tiempo entraban en una senda de fragmentación interna. Simultáneamente los republicanos, que ya habían hecho su particular aprendizaje en la esfera del gobierno local, fluctuaron de la participación al retraimiento. E incluso, algunos, generalmente los posibilistas, se avinieron a integrarse en alianzas contranatura con los conservadores y los carlistas cuando sus intereses políticos podían verse perjudicados. En realidad, el régimen promovía deliberadamente este tipo de alianzas con el fin de neutralizar la oposición y encauzarla hacia sus propios derroteros.

En esta década un nuevo actor político irrumpió con fuerza en la escena ciudadana: el catalanismo de signo conservador. Este rechazó sistemáticamente intervenir directamente en los comicios electorales, aunque no a ofrecer apoyo público y explícito a los candidatos de su preferencia, normalmente conservadores o carlistas. Como tampoco no dudó en incidir sobre la opinión pública con un rotativo propio en el que expresaría, junto con su ideario político, una profunda aversión y rechazo a la política de la Restauración para convertirse en un invitado de piedra de los entresijos del poder local. Por otro lado, este catalanismo participó en la movilización de los ciudadanos mediante la organización de campañas en la defensa de la lengua catalana, a favor del derecho a la autonomía de las últimas colonias de ultramar o, su protagonismo indiscutible en el célebre Tancament de Caixes, para citar las más importantes.

El movimiento obrero organizado, así como el núcleo socialista existente en la ciudad, también se situaban en las antípodas del sistema o, más claramente fuera de él, junto a los sectores republicanos que finalmente se decantarían por el abstencionismo electoral permanente. A pesar de no disponer de una investigación especializa- 
da sobre el movimiento obrero en la ciudad, sí que podemos intuir que el sindicalismo manresano estuvo muy influido por el socialismo, especialmente después de las huelgas de $1890^{8}$. Efectivamente, a finales del siglo XIX, los socialistas manresanos realizaron auténticos esfuerzos de aproximación al mundo sindical. Contribuyeron decididamente a la reorganización de las sociedades de oficio y convencieron a los sindicatos sectoriales para que reivindicaran la jornada de 8 horas y participaran en las manifestaciones del primero de mayo. A nivel político, por otra parte, seguramente se produciría un acercamiento entre el republicanismo que empezaba a liderar el abogado Maurici Fius i Palà hasta el punto que en 1899 era elegido un concejal de esta tendencia política. También y no por casualidad abundaron los calificativos de socialistas a Fius y sus acólitos?.

\section{El despertar cívico de las clases medias y el descuaje del caciquismo}

En la determinante coyuntura del final de siglo se forjaron las bases del cambio político que se iría materializando durante los dos primeros decenios del siglo XX. Este modelo de cambio se basaría en un bipartidismo republicano/regionalista; en la persistencia de las relaciones clientelares en la política local; en el progreso notable del voto verdad y con él de la autentificación del sufragio y de la política competitiva; en el protagonismo de los sectores católicos y regionalistas como desencadenantes de la descomposición del turno dinástico; y, finalmente, en la conversión del republicanismo como alternativa de gobierno. Entre 1899 y 1902, católicos, regionalistas y republicanos abanderaron la protesta de las clases productivas. En este ambiente de protesta y de movilización participó el clero más integrista que organizaba sus peroratas desde la prensa y el altar en contra de los gobiernos centrales que, según su parecer, cometían el inmenso error de tolerar las ideas más avanzadas del socialismo.

Sin embargo, esta estrategia que abrazó una parte considerable del clero manresano pronto demostró síntomas de agotamiento desde el momento que creaba desunión y desconcierto entre los católicos y de pasada desprestigiaba a la institución eclesiástica. La decadencia de esta vía abrió paso a una táctica más moderada impulsada por unos sectores más amplios y heterogéneos y que empezaba a arropar la causa de la Lliga Regionalista, el partido del catalanismo conservador recientemente creado en Barcelona (1901) y que se convertiría con el paso del tiempo en el nuevo partido de orden. Por otro lado, los republicanos aprendieron una gran lección, la de que les era muy conveniente mantener buenas relaciones con el arcipreste de la ciudad para que tuviera controlada la acción moralizadora y politizadora de los curas de las parroquias.

${ }^{8}$ La Agrupación Obrera Socialista fue creada en 1892 y a finales de siglo solo tenía 17 miembros. Su fuerza decayó en el transcurso del primer decenio del siglo XX, hasta 1931 cuando intentó de nuevo recuperarse.

${ }^{9}$ RUBI, Gemma: "Maurici Fius i Palà (1863-1920). Un polític republicà de la Catalunya de principi de segle" en Profesor Nazario González. Una historia abierta, Barcelona, Universitat de Barcelona, 1998, pp. 351-362. 
Por tanto, el despertar cívico de las clases medias y su politización en un sentido catalanista estuvo muy relacionado con la movilización del catolicismo político. Un rasgo que diferenciaría el modelo de cambio político manresano si lo comparamos con el de la ciudad de Barcelona, si bien al mismo tiempo lo aproximaría al que experimentaron otras ciudades como Vic, Vilanova i la Geltrú, Castelló de la Plana o Vitoria, entre otras ${ }^{10}$. Paralelamente los republicanos también participaron de esta intensa politización mediante la celebración de mítines a favor de la revisión de los procesos de Montjuïc o en su participación en el Tancament de Caixes. Incluso un político dinástico como el fabricante Lluís Vila i Miralles fue uno de los promotores de la Liga de Productores de la ciudad. Para unos y otros, la coyuntura de fin de siglo les sirvió como terreno de aprendizaje del peso y significado que más tarde tendría la opinión pública en la vida política local.

El acceso masivo de las clases medias se produjo pues a través de estos episodios de intensa politización. A diferencia de la primera etapa de la Restauración, estos episodios se convirtieron en una forma normal de expresión colectiva de las demandas y reivindicaciones de los ciudadanos. En efecto, durante los años del sufragio censatario la politización era sinónimo de luchas tribales entre los grupos políticos que tenían el privilegio de participar en el sistema y que se reflejaba fundamentalmente en la prensa. La calle todavía no era el ámbito normal de expresión de estas tensiones. Lo normal era la prohibición de manifestaciones que tendieran a criticar el orden establecido como el mismo carnaval. De todas formas, esta ausencia de verdadera politización no significaba que no existieran conflictos, aunque estos no repercutían en alterar una relativa estabilidad política.

\section{La entronización de un nuevo bipartidismo catalanista-republicano}

Durante los primeros decenios del siglo XX, en la esfera del poder local se forjó un bipartidismo que enfrentaba dos bloques de poder muy diferenciados y que actuaban en política como portavoces de las derechas y de las izquierdas ${ }^{11}$. El bloque católico y regionalista estaba formado por fabricantes partidarios del paternalismo como forma de integración y de neutralización de las luchas sociales extendido en algunas fábri-

\footnotetext{
${ }^{10}$ MARTI, Manuel : Cossiers y anticossiers. Burgesia y politica local: Castelló de la Plana, 18751891, Castelló, Diputació Provincial de Castelló, 1985; del mismo autor: El Ayuntamiento de Castelló de la Plana (1875-1891). Del triunfo de la Restauración al ascenso de la nueva política, Castelló, Ayuntamiento de Castelló de la Plana/Diputación provincial de Castelló, 1989. RIVERA, Antonio: La ciudad levítica: continuidad y cambio en una ciudad del interior. Vitoria, 1876-1936, Vitoria, Diputación Foral, 1992. Finalmente, TORNAFOCH, Xavier: Catalanisme, carlisme i republicanisme a Vic (1899-1909): modernització política i lluites socials, Barcelona, Publicacions de l'Abadia de Montserrat, 2002; y, CANALES, Antonio Francisco: Passatgers de la mateixa barca. La dreta de Vilanova i la Geltrú, 1903-1979, Lleida, Ajuntament de l'Alguaire, 1993.

${ }^{11}$ RUBÍ, Gemma: "Formes i mecanismes de continuïtat del poder en l'espai local. III. Del consens caciquil a una nova legitimitat política del poder: els casos de Vilanova i la Geltrú i de Manresa" en Formes i relacions del poder local a l'època contemporània. II Congrés Internacional d'història local de Catalunya, 1993, Barcelona, L'Avenç, 1995, pp. 103-116.
} 
cas de río y en las colonias textiles del río Llobregat donde se prodigaba un auténtico paternalismo social. En este sector, figuraron el fabricante Fermí Roca i Coma, jefe del integrista comité de Defensa Social y futuro miembro de la Unión Patriótica de Manresa, las familias carlistas de los Gomis y de los Vidal; grandes comerciantes como los Armengol, próximos al carlocatolicismo; y, los propietarios de tierras regadas por el canal de la Sequia que proporcionaba agua a la ciudad desde el siglo XIV. A escala electoral, este bloque estaba integrado por la Lliga Regionalista, los carlistas y el sector romanonista del partido liberal.

El otro bloque político -que era el dinástico conservador- actuaba como un poderoso grupo de presión en el que se integraban los intereses del sector textil (los Borrás, Gallifa, Vila, Pons i Enrich) y los de la electricidad. En este lado se alinearon los republicanos liderados por el abogado y alcalde Maurici Fius i Palà, que había conseguido aglutinar el republicanismo manresano. En el ámbito local, políticamente se expresaba como republicano y portador del mensaje de una izquierda reformista. En él también se sumó el grupúsculo jaimista del carlismo partidario de los requetés y de una acción más beligerante del carlismo en la sociedad. Igualmente, por su parte el grueso de la jerarquía eclesiástica también consideraba como más "políticamente correcto" a este bloque de poder.

Este bipartidismo republicano/regionalista era expresión de unas alianzas estables que se afianzaron en los albores del siglo XX. Contrariamente, con anterioridad y especialmente durante la década de los años noventa del siglo anterior las alianzas entre grupos o facciones habían revestido un carácter más táctico e inestable. En la representación a Cortes, desde 1899 hasta 1923 la Lliga Regionalista controló el escaño de Manresa, con la sola excepción de las legislaturas comprendidas entre 1910 y 1916 que pasó a manos del partido conservador ${ }^{12}$.

\section{Pluralismo político, competencia electoral y clientelismo}

A partir de la coyuntura de fin del siglo XIX, la vida política se nutrió de un pluralismo político que expresaba intereses también de naturaleza colectiva, y no solo individual, y con ellos una visión de la sociedad manresana y del mundo también plurales. Este pluralismo político no solo se manifestaba en la creación de un sistema de partidos local, que la misma lógica del sistema electoral reconducía hacia un bipartidismo, sino también en la acusada fragmentación política que se observaba en la esfera pública. Todas las tendencias políticas de la época estaban presentes. Todas se alimentaban de las tradiciones políticas que procedían del Sexenio Democrático, aunque una, la catalanista, acabó cuajando en la vertiente de derechas, la Lliga Regionalista, y en la de izquierdas, con el republicanismo de signo nacionalista ${ }^{13}$. Paralelamente la

${ }^{12}$ RUBÍ, Gemma: “Quan la influència política s'inverteix i la Lliga perd provisionalment l'hegemonia. El districte de Manresa entre 1910 i 1914" en Afers. Fulls de Recerca i Pensament, no 53-54, 2006, pp. 209-228.

${ }^{13}$ Profundizo en las culturas políticas de la Restauración y en el republicanismo nacionalista en: RUBÍ, Gemma: "Les cultures polítiques de la Catalunya contemporània interactuant en un marc urbà. 
existencia de estas tendencias había partido de los ejes de conflicto existentes en los regímenes liberal-democráticos europeos y que han explicado, según los análisis del profesor Stein Rokkan, los alineamientos electorales y la adscripción partidista, es decir, las fracturas social, religiosa y nacional, respectivamente ${ }^{14}$.

La lenta consolidación de una política competitiva se tradujo en la práctica en la creación de un mercado electoral propio en el que diferentes partidos competían por la distribución del voto. Lo hacían intensificando los medios de propaganda a través de campañas electorales que consistían en mítines cada vez más concurridos y en los tradicionales canales de la demanda del voto puerta a puerta. La prensa siguió jugando un papel esencial como portavoz de los diferentes proyectos políticos y caja de resonancia de los debates de la política local. El voto auténtico, que ya tenía una presencia notable en la ciudad pero no en el distrito, experimentó un avance muy considerable. Naturalmente la comisión de fraude electoral progresivamente se hizo más complicada y sobre todo menos legitimada porque las fuerzas que competían entre si eran de la oposición y su lema era la pureza del sufragio. La presencia de interventores en los colegios electorales y el control del censo contribuyeron por otra parte a este avance.

Aún así, a medida que el voto era más difícil de controlar mediante las prácticas caciquiles recurrentes, sí que aumentó significativamente la compra de votos y especialmente la negociación del voto procedente de las organizaciones de intereses. Junto a la persistencia del favor y de la preferencia, que discriminaba beneficios indivisibles de carácter público personalizándolos, de forma progresiva veremos consolidarse otro tipo de clientelismo de carácter transaccional, efímero y de baja fidelidad. En multiplicarse los votos se multiplicaban paralelamente los favores y la negociación a cambio de intereses puntuales o de la satisfacción de demandas puntuales. Esta manera de proceder tanto la utilizaban los regionalistas como los conservadores. Para todos ellos, sin diferencias, esta era una empresa política nueva.

La importante existencia de relaciones clientelares nos priva de poder hablar directamente de democracia de masas, aunque no de un estadio inmediatamente anterior a su advenimiento ${ }^{15}$. La realización de campañas electorales de signo moderno al final del periodo y la celebración de mítines no fueron incompatibles con la conti-

Manresa durant la Restauració" en Rassegna Iberistica, no 84, 2006, pp. 61-75; "Republicanismo y nacionalismo en Cataluña a principios del siglo XX: un anàlisis comarcal" en Mariano ESTEBAN DE VEGA; María Dolores DE LA CALLE VELASCO (eds.): Procesos de nacionalización en la España contemporánea, Salamanca, Ediciones Universidad, 2010, pp.115-131. También, de Santiago IZQUIERDO; Gemma RUBÍ: "El Centre Nacionalista Republicà (1906-1910) i el catalanisme d'esquerres" en Cercles. Revista d'història cultural, $\mathrm{n}^{\circ}$ 11, 2008, pp. 106-122; y, de los mismos autores como coordinadores: Els orígens del republicanisme nacionalista. El Centre Nacionalista Republicà a Catalunya, 1906-1910, Barcelona, Generalitat de Catalunya, 2009.

${ }^{14}$ FLORA, Peter (ed.): State formation, nation-building and mass politics in Europe: the theory of Stein Rokkan, London, Oxford University Press, 1999.

${ }^{15}$ RUBÍ, Gemma: «Caciquisme et changement dans les villes catalanes : le cas de Manresa sous la Restauration (1875-1923 » en Bulletin d'Histoire contemporaine de l'Espagne, $\mathrm{n}^{\circ}$ 45, 2011, pp. 4365. También, "Clientélisme, corruption et mobilisation électorale dans l'Espagne contemporaine. Catalogne, 1900-1923” en Siècles. Cahiers du Centre d'histoire des entreprises et des communautés, Université Blaise Pascal/Clermont-Ferrand II , nº 31, 2012 (en prensa). 
nuidad del componente clientelar, tanto individual como grupal. Por este motivo, era necesaria la articulación de una red social y institucional que proporcionara apoyos electorales, aunque el grueso de los votos había que renegociarlos de legislatura a legislatura. Probablemente las elecciones que comportaban menos trabajo a sus candidatos eran las provinciales las cuales a lo largo del periodo considerado siguieron rigiéndose por los mismos procedimientos del pasado consistentes en pactar previamente los resultados.

En otro sentido, tampoco estamos frente a un tipo de clientelismo que podamos equiparar al actual clientelismo de partido o de masas ${ }^{16}$. De todas formas, nos preguntamos hasta qué punto el componente clientelar, percibido como el elemento sombrío de la política, no ha desparecido del todo en la política actual cuando esta se considera netamente democrática. Lo corroboran los programas cada vez más simplificados que lanzan los partidos políticos, así como el contenido ideológico ha dejado paso a una concepción más mercantil del voto. No obstante, no podemos ignorar que los distritos uninominales como el de Manresa acompañados de un escrutinio mayoritario tendieron a favorecer una relación estrecha entre el diputado y sus electores, y por esta razón la inclinación a intercambiar votos por favores. Por otra parte, en las elecciones locales el conocimiento de los candidatos, en la mayoría de los casos residentes en los distritos en los que se presentaban, y la gran proximidad entre estos y los electores, alimentaba paralelamente el control individual y institucional del voto. Finalmente, sólo indicar que era muy rentable para una candidatura deslegitimar la contraria acusándola de haber cometido fraude y corrupción, cuando muchas veces estas acusaciones no se podían comprobar fácilmente.

\section{Nuevas formas de partido surgen en la Cataluña de principios del siglo XX}

En Cataluña la transición del partido de notables al de masas se produjo a través de la aparición de los partidos basados en la afiliación indirecta, no del militante, sino de las entidades políticas locales que conservaban, así, su autonomía. El partido de afiliación indirecta se define por estar organizado de forma horizontal, por la ausencia de una estructura democrática en la relación entre las sedes locales y la dirección central, y fundamentado en la adhesión de carácter voluntario. El partido de la Lliga Regionalista se adecua perfectamente a esta modalidad de transición, así como el resto de partidos republicanos. Mientras que el partido republicano lerrouxista empezó a adoptar las formas organizativas de un verdadero partido de masas, si bien mantuvo la misma relación horizontal entre la dirección central y las sedes locales. En todos los casos, los partidos adaptaron las estructuras organizativas hacia la creación de maquinarias electorales destinadas a la movilización del voto. Esta transformación del modelo organizativo, en líneas generales, coincidió con el paso del partido de

${ }^{16}$ CAZORLA PÉREZ, José: "El clientelismo de partido en la España de hoy: una disfunción de la democracia" en Antonio Robles Egea (comp.), Política en penumbra. Patronazgo y clientelismo políticos en la España contemporánea, Madrid, Siglo XXI, 1996, pp. 291-310. 
notables, esencialmente clientelar, al partido de encuadre, más disciplinado, aunque no podemos asimilarlo sin más al moderno partido de masas.

En el ámbito meramente local, la tesis de las anillas de sociabilidad que he definido para el caso manresano nos permite explicar cómo funcionaba la socialización política en esta sociedad. El aprendizaje de la política y la asimilación de una ideología determinadas se llevaba a cabo a través de diferentes niveles de influjo partidista, que al mismo tiempo se convertían en auténticos espacios de comunicación política. En un primer nivel de transmisión de las diversas culturas políticas -partiendo del supuesto que estas no sólo se generaban en los centros políticos respectivos-, se situarían los partidos como tales y las asociaciones que estaban alimentando la militancia política pese a no estar constituidas formalmente como partidos. Un segundo nivel vendría representado por el abanico de entidades de carácter cultural, moral y religioso, y de recreo, que no ejercían una función política directa, pero que eran correas de transmisión de la adscripción simbólica dentro del universo político ciudadano. A menudo los dos niveles confluían en uno sólo, los ateneos, que más que un club cultural eran la unidad política de base de la sociedad catalana precisamente por el carácter aglutinante que ejercían, puesto que eran centros de sociabilidad de barrios, calles o pueblos. Finalmente, entendemos que sería conveniente integrar en el proceso de socialización de la política a otros agentes como la familia y la escuela, junto a las experiencias de clase resultantes de las diversas ubicaciones en el mundo del trabajo y de la defensa de la propiedad.

\section{Los ingredientes del cambio}

El profundo cambio político experimentado por la sociedad manresana se basó en el acceso por parte de los auténticos partidos sociales a la vida política oficial, restringida en otros tiempos a los partidos dinásticos. Como canalizadores de los intereses colectivos, los partidos "sociales", o de arraigo social, recurrieron a la politización permanente en la calle, la prensa, la publicística y las contiendas electorales. Unos verdaderos partidos de arraigo popular que tendieron a tejer unas alianzas de poder que cristalizaron en nuevos bloques políticos a través de los que las viejas clases dominantes intentaron intervenir de una manera decisiva en la distribución del poder a nivel local. Sin embargo, ningún partido, como hemos visto anteriormente y si nos atendemos a los parámetros de la modernidad política, se convirtió plenamente en partido de masas. Solamente en partidos de afiliación indirecta, un estadio intermedio entre aquellos y los de notables, y uno, el republicano liderado por el abogado Fius, se aproximó a la tipología del partido de masas.

Mientras la movilización política se había manifestado de una forma intermitente en el pasado, fundamentalmente durante el Sexenio Democrático, a partir de la descomposición del turno dinástico, el debate político ciudadano, las elecciones competitivas y el triunfo de las ideologías pasaron a convertirse en la nota preponderante de un nuevo escenario político que bien puede calificarse como la antesala de la democracia de masas. Los protagonistas indiscutibles de este nuevo escenario fueron 
los catalanistas, los carlistas y los republicanos. Aunque no podemos despreciar los esfuerzos que llevaron a cabo los partidos dinásticos para adaptarse a la nueva situación y desarrollar estrategias de competición electoral.

En definitiva, la gran novedad que se produjo a partir de 1901 fue el avance claro de la democracia, pese a que el sistema político seguía rigiéndose por los principios de un liberalismo esencialmente no democrático. Sin embargo, el retroceso de la política oligárquica no impidió que las relaciones clientelares siguieran siendo la piedra de toque, en muchos casos decisiva, en el control del poder local ${ }^{17}$. En este sentido, hubiera sido interesante comparar de forma exhaustiva las redes clientelares del diputado de la Lliga Regionalista, Leonci Soler i March, y del conservador maurista, Lluís Vila Miralles. Pero intuimos de forma clara que ambos diputados gozaban de unos apoyos sociológicos similares, aunque el traspaso de lealtades entre uno y otro no fue seguramente una empresa fácil. De otra forma no podríamos entender el porqué en 1910 Soler perdió tan fácilmente el acta parlamentaria en favor de los conservadores.

Naturalmente, el peso del elemento eclesiástico era muy superior en la red social y política de los catalanistas. Ganarse la confianza de los curas de los pueblos significaba tener asegurado el éxito en la obtención de votos. Igualmente el grueso de los propietarios rurales confiaba en la intermediación del diputado regionalista. Por contra, una parte muy importante de los propietarios de las colonias industriales tenían una adscripción dinástica conservadora, así como algunos fabricantes de la industria textil. Soler i March contaba con el apoyo incondicional de los catalanistas, de los nocedalinos, de los carlistas y de los socios de la Juventud Católica, así como de las asociaciones piadosas. Igualmente, reclutaba votos entre los campesinos, y entre una parte significativa de los comerciantes y de algunos trabajadores de oficio.

El avance del voto verdad obligó a los dinásticos a competir en la arena electoral, aunque lo hicieron con unas dosis crecientes de corrupción política. Los conservadores eran pocos pero muy poderosos y estaban muy acostumbrados, mucho más que otros, a la política del favor y de la recomendación. Por esta razón, el diputado Lluís Vila fue capaz de construir una red social de fidelidades al menos tan eficaz como la del diputado de la Lliga ${ }^{18}$. Como aquél, en cada municipio tenía agentes electorales y confidentes que lo informaban puntualmente de las batallas políticas locales. También tenía suficiente capacidad financiera para sufragar unas elecciones. Las de 1916, que no logró ganar, le costaron la cifra de 7.914,25 pesetas que fueron destinadas a pagar los trabajos de los agentes electorales, los gastos notariales, "los" interventores y electores adictos, teléfono, banquetes, etc ${ }^{19}$.

${ }^{17}$ MARIN, Manuel: Clientélisme et domination politique en Espagne. Catalogne à la fin du XIXème siècle, Paris, L’Harmattan, 2006; RUBÍ, Gemma: “Existían caciques y cacicatos en Cataluña a finales del siglo XIX? Unas reflexiones a propósito del libro de Manuel Marin, Clientélisme et domination politique en Espagne. Catalogne à la fin lleva XIXe siècle, Paris, L'Harmattan, 2006" en Cahiers de civilisation espagnole contemporaine, $\mathrm{n}^{\circ} 3,2008$.

${ }^{18}$ Una primera aproximación al análisis de las redes sociales en Política y Sociedad, no 33, (Eneromayo, 2000), pp. 11-206. También, MOLINA, José Luis: El análisis de redes sociales. Una introducción, Barcelona, Edicions Bellaterra, 2001.

${ }^{19}$ Correspondencia de Lluís Vila i Miralles sobre las elecciones legislativas de 1916, s/c, Arxiu Històric Comarcal de Manresa. 
Les elecciones generales de 1916 constituyeron un barómetro que sirvió para sopesar las fuerzas de conservadores y regionalistas. El comerciante de maderas manresano, Leandre Vila recordaba al candidato dinástico Lluís Vila i Miralles, que esta vez "la cosa irá muy empeñada, es preciso recoger todas las migas" 20 . La correspondencia epistolar que recibió Vila durante la campaña electoral pone de manifiesto el tipo de apoyos con que contó. Unos votos procedían de las clases obreras que trabajaban en el sector textil, votos que eran reclutados directamente y por encargo a través de los republicanos; otros votos los emitían los directores de estos centros fabriles, como los de la colonia Palà de Torroella en la cuenca del río Cardener o los de Castellbell i el Vilar. El análisis de los comicios de 1919 pone de manifiesto que los apoyos sociales a los republicanos seguían siendo los mismos ${ }^{21}$.

El acta de diputado la obtuvieron finalmente los catalanistas de la Lliga. Los conservadores fueron derrotados de una manera, como ellos mismos lo expresaron, ignominiosa. Las pruebas que Vila aportó al Tribunal Supremo, encargado de juzgar la legalidad del acta, son en este sentido muy elocuentes. Por tanto, incluso a finales del periodo restauracionista no eran suficientes las grandes promesas colectivas, ni tampoco los principios ideológicos que alimentaban las fracturas religiosa, social y nacionalista, sino que el comportamiento clientelar siguió siendo una fuente permanente de movilización del electorado. Sin embargo, Vila perdió el escaño en parte por el retraimiento del voto republicano, pese a los esfuerzos de reclutamiento clientelar llevados a cabo.

A diferencia de la ciudad de Barcelona, fueron los católicos regionalistas los grandes impulsores del cambio político que tuvo lugar en la coyuntura de final de siglo, así como los aglutinadores de la derecha a partir de entonces. Decidieron que tenían que movilizarse e intervenir de forma activa en las contiendas electorales. El conglomerado formado por católicos, catalanistas, carlistas, integristas y conservadores decepcionados fue la base política de la nueva derecha liderada por el abogado y hacendado Leonci Soler y March. Este rol también lo ejercieron católicos y carlistas en ciudades del Norte de España como Pamplona o Vitoria ${ }^{22}$. En la ciudad de Vic, Xavier Tornafoch advierte un impulso de renovación política realizado por catalanistas y carlistas que en las elecciones de 1899 consiguieron desbancar a los dinásticos.

Por su parte, los conservadores fueron lo suficientemente hábiles para captar la simpatía del republicanismo mayoritario. Con esta alianza contranatural podían discutir la preeminencia de los regionalistas y carlistas en el panorama local manresano. Como en otras ciudades catalanas, Sabadell y Reus entre otras, el republicanismo

\footnotetext{
${ }^{20}$ Carta de Leandre Victori a Lluís Vila, del 27 de marzo de 1916. Documentación de la Junta del Hospital de Sant Andreu (A.H.C.M.).

${ }^{21}$ Documentación electoral del candidato republicano Jesús Pinilla en las elecciones generales de 1919 (Archivo Abel Pascual i Ventosa).

${ }^{22}$ LARRAZA, María del Mar: "Estudio de las bases sociales de los partidos políticos en Pamplona, 1890-1923" en FORNER, Salvador (coord.): Democracia, elecciones y modernización en Europa. Siglos XIX y XX, Madrid, Cátedra, 1997, pp. 347-378; y en VARELA ORTEGA, José (dir), El poder de la influencia. Geografía del caciquismo en España (1875-1923), op. cit., pp. 433-453. Para la ciudad de Vitoria, RIVERA, Antonio: La ciudad levítica. Continuidad y cambio en una ciudad del interior (Vitoria, 1876-1936), op. cit.
} 
era una tendencia que gozaba de una gran vitalidad. Los liberales, muy divididos, optaron por favorecer la política posibilista del republicanismo reconvertido y cohesionado por Maurici Fius, o por intentar ocupar el espacio liberal y demócrata, reorganizándose. Este fue el caso del Círculo Liberal Popular, la fracción romanonista del partido liberal, aunque siempre actuó a nivel electoral como satélite de la Lliga Regionalista dentro de un mismo frente común.

En un proceso de modernización de los postulados doctrinales y de la acción política, los republicanos fueron prioritariamente los representantes de las clases obreras, populares y de una parte muy importante de las clases medias urbanas. Esta vitalidad permitió la configuración de un bloque de poder que se enfrontó sistemáticamente al bloque de la derecha que articulaba el voto conservador y católico. En realidad, este movimiento ocupó el espacio político que en otros lugares cubría el partido socialista, o los republicanismos blasquista y lerrouxista, existentes en Valencia y Barcelona, respectivamente.

El nuevo turno que se impuso en la ciudad de Barcelona entre regionalistas y republicanos se reprodujo con gran similitud en Manresa. Sin embargo, esta no fue la tónica general en Cataluña. En Vilanova i la Geltrú, los católicos desarrollaron una movilización política paralela a la manresana y fueron capaces de liderar el nacimiento de una derecha moderna que se conoció en la época como el vilanovismo político. Pero, a diferencia de Manresa, los republicanos, igual que en la ciudad de Vic, no lograron convertirse en una alternativa real en el gobierno local.

\section{Un caciquismo renovado}

En la etapa de transición de la vieja a la nueva política que estamos analizando, el componente clientelar persistió pero cambió de talante. Irónicamente, se trataba de convertir en adictos, no los notables del turno como en el pasado, sino a las organizaciones de intereses. Por esta razón, surgió un nuevo tipo de clientelismo que forzosamente tenía que satisfacer a los agentes que detentaban poder social, como los propietarios rurales, los fabricantes o los eclesiásticos, entre otros colectivos ${ }^{23}$. Pero también a los intereses organizados de la clase obrera, de los pequeños industriales, de los campesinos, dependientes del comercio y de la industria, y los de los trabajadores de los oficios.

En efecto, la ampliación del sufragio permitió la expresión de las demandas de estos sectores. Si el caciquismo quería sobrevivir en un escenario en el que los partidos dinásticos habían perdido el control directo del poder, tenía que tener en cuenta estas demandas y convertirlas en fuente de intercambio clientelar. De forma paralela, se subvertía la lógica del clientelismo propio de las sociedades tradicionales, en las que las fidelidades eran casi eternas, mientras que ahora adquirieron una naturaleza mercantil, sujeta a la fugacidad del intercambio del mercado.

${ }^{23}$ Un fenómeno similar que Miguel Cabo ha observado para Galicia: "Leyendo entre líneas las elecciones de la Restauración: la aplicación de la ley electoral de 1907 en Galicia" en Historia Social, $\mathrm{n}^{\mathrm{o}} 61,2008$, pp. 23-43. 
Este nuevo clientelismo acompañó a un tímido proceso de democratización que se abría paso lentamente y que estaba ya movilizando a las clases medias y a los sectores populares a través de una política de masas y de una democracia muy embrionaria. No obstante, la falta de consolidación del proceso de politización en un sentido democrático no invalidó los grandes avances producidos en esta etapa. Todo ello a pesar de la crisis política y social que desembocó en la solución autoritaria de Primo de Rivera. De otra manera no entenderíamos la irrupción de los grandes partidos de la Segunda República y su éxito electoral, como tampoco la naturaleza de los factores de politización de este período histórico.

\section{Un callejón sin salida democrática}

En 1923 la vida política manresana había cambiado de tal forma que no era posible dar marcha atrás. Los cambios experimentados eran irreversibles, a pesar de que los límites de la modernización se manifestaron en síntomas como el cansancio de los electores que progresivamente participarían menos. Pero también y de forma muy significativa en el comportamiento de los partidos políticos y en las actitudes de las élites de poder. El trasfondo de la crisis social que se inició a partir de 1917 sería un escenario poco propicio para un afianzamiento sereno y reposado de la democracia. Por una parte, porque las clases obreras retiraron su apoyo incondicional al republicanismo y prefirieron instalarse en el apoliticismo. Por otra, porque los republicanos, se vieron embargados por la desorientación y el desconcierto. En realidad, su proyecto político había tocado fondo. Desde 1915, la alianza con los republicanos nacionalistas había demostrado ser muy rentable para sus intereses electorales, si bien a la vez ponía de manifiesto que el republicanismo, si quería sobrevivir, tendría que tener acento catalanista. De ahí, el giro experimentado hacia la defensa de la autonomía de Cataluña, algo inimaginable durante la coyuntura de Solidaridad Catalana, cuando el grueso de los republicanos manresanos fueron de los pocos que se declararon antisolidarios.

Las derechas también acusaron su propia crisis. En las elecciones municipales de 1922 el hermético bloque de derechas se escindió y se presentaron dos candidaturas alternativas, la de la Lliga, y la formada por carlistas y catalanistas conservadores desengañados que a pesar de todo tampoco triunfaría. Sin embargo, los verdaderos enemigos eran los dinásticos reciclados en la plataforma de la Unión Monárquica Nacional, el último canto del cisne de unos partidos que en Cataluña casi ya no disfrutaban de ningún resquicio de credibilidad. Al mismo tiempo, las juventudes nacionalistas de la Lliga corearon el triunfo del naciente partido "Acció Catalana" en los comicios provinciales de Barcelona.

Unas transformaciones que se desarrollaron a pesar de la ausencia de una voluntad clara de democratización del sistema político manifestado por sus élites dirigentes. Simplemente porque la sociedad estaba cambiando y las formas de ejercicio del poder y los estilos de hacer política también y los existentes como canales de representación no eran los más adecuados. Achacar toda la responsabilidad a unas elites que tenían 
monopolizado al Estado en un sentido patrimonial y que por esta razón no deseaban introducir ninguna reforma que discutiera esta preeminencia nos parece desproporcionado. Porque estamos atribuyendo a estas elites demasiado protagonismo en un proceso de cambio político causado por un haz complejo de factores ${ }^{24}$. El proyecto político de Cánovas del Castillo no había contemplado nunca la incorporación de la dimensión democrática a un régimen que se deseaba de corte eminentemente liberal. La reintroducción del sufragio universal en 1890 obedeció a una vieja aspiración de los sectores más liberales del sistema. Por descontado, su recuperación supuso una mayor oportunidad para las oposiciones de expresión y de representación políticas, aunque no la panacea de la democratización del sistema político.

La actuación de estos partidos situados al margen del sistema tampoco fue un claro acicate de la regeneración del sistema, a pesar de los esfuerzos realizados, muchas veces sin éxito ${ }^{25}$. Se adaptaron a unas reglas de juego que favorecían la política caciquil y aprovecharon los pocos indicios de apertura del sistema y sobre todo su desintegración para avanzar y consolidarse. Pero no se les podía pedir más. Fueron portavoces de una sociedad que progresivamente iba articulando sus intereses y se convertía en más plural. Al mismo tiempo, estos partidos se consolidaron definitivamente en aquellas ciudades y distritos electorales, como el de Manresa, en los que los partidos dinásticos ya habían perdido el monopolio político desde principios del siglo XX.

\footnotetext{
${ }^{24}$ Los principales debates sobre la crisis de la Restauración en SUÁREZ CORTINA, Manuel: "La Restauración (1875-1900) y el fin del imperio colonial (1875-1900). Un balance historiográfico" en $L a$ Restauración, entre el liberalismo y la democracia, Madrid, Alianza Universidad, 1997; del mismo autor, La crisis del Estado liberal en la Europa del Sur, Santander, Sociedad Menéndez Pelayo, 2000; BAHAMONDE, Angel (coord.): Historia de España Siglo XX. 1875-1939, Madrid, Cátedra, 2000; GARCÍA SANZ, Fernando (ed.), España e Italia en la Europa contemporánea: desde finales del siglo XIX a las dictaduras, Madrid, CSIC, 2002; CABRERA, Mercedes: "Elecciones y cultura política en la crisis de la monarquía de la Restauración" en GUTIÉRREZ, Rosa Ana; ZURITA, Rafael; CAMURRI, Renato (eds.): Elecciones y cultura política en España e Italia (1890-1923), València, Publicacions de la Universitat de València, 2003, pp. 189-196.

${ }^{25}$ RUBÍ, Gemma; ESPINET, Francesc (eds.): Solidaritat Catalana i Espanya (1905-1909), Barcelona, Editorial Base, 2008.
} 